\title{
Perder e Recuperar a Alma: Tendências Recentes na Psicologia Social da Religião Norte-Americana e Européia ${ }^{1}$
}

\author{
Geraldo José de Paiva ${ }^{2}$ \\ Universidade de São Paulo
}

\begin{abstract}
RESUMO: A palavra alma, do vocabulário religioso e psicológico, desapareceu da linha-mestra da psicologia. Com ela desapareceu o conceito de uma instância essencial da realidade humana. Ao contrário das denotações que identificam alma, espírito e mente e contrapõem alma a corpo, parece possível restituir a articulação originária dessas palavras nas fontes hebraicas da Bíblia, nas expressões idiomáticas das línguas ocidentais e no vocabulário psicológico fundador. Não é o uso da palavra alma, mas a recusa de seu desemprego, que torna interessante para o psicoterapeuta a serviço da alma, a atenção para estudos recentes, norte-americanos e europeus, que tentam restituir à alma sua posição estrutural e dinâmica na psique.
\end{abstract}

Palavras-chave: alma; coração; mente; psicoterapia; psique; vocabulário psicológico

\section{On Losing and Restoring the Soul: Contemporary Trends in American And European Social Psychology of Religion}

\begin{abstract}
Soul, a religious and psychological word, has disappeared from mainstream Psychology. Along with it, the concept of an agency essential to humanness has also disappeared. Instead of the denotations unifying soul, spirit and mind, and opposing soul to body, it seems possible to restore the original relationship between those words from the Hebraic biblical sources, some idiomatic expressions of western languages, and the founding psychological vocabulary. It is not so much the use of the word soul, as the refusal to not using it that makes it interesting to the psychotherapist to pay attention to recent American and European studies that attempt to give again the soul its structural and dynamic standing in the psyche.
\end{abstract}

Key words: soul; heart; mind; psychotherapy; psyche; psychological vocabulary

"corpo, este hóspede estranho da alma" (Adélia Prado, Filandras: 89)

\begin{abstract}
Alma e Mente
Um bom início para a discussão do emprego do vocábulo alma na Psicologia em geral e no trabalho terapêutico em particular pode ser a polêmica de B. Bettelheim (1993) com a tradução inglesa da Standard Edition das obras de Freud. Embora não levantasse dúvida quanto à competência dos tradutores e reconhecesse a chancela editorial da própria Anna Freud, Betelheim os censura por terem cedido à intenção de tornar "científicos" os termos muitas vezes singelos de Freud. Um desses termos, que no Índice das Gesammelte Werke ocupa duas colunas, é o de Seele, literalmente $a l m a^{3}$. Esse vocábulo foi vertido para o inglês como mind, em sentido literal mente, e não como soul, seu correspondente

1 Versão de texto apresentado na XXXI Reunião da Sociedade Brasileira de Psicologia, Rio de Janeiro, de 24 a 27 de outubro de 2001, integrando a Mesa-redonda "Contribuições da Psicologia da Religião para o trabalho psicoterápico".

2 Endereço: Departamento de Psicologia Social e do Trabalho do Instituto de Psicologia da Universidade de São Paulo. Av .Prof. Mello Moraes, 1721, Cidade Universitária, 05508-900 São Paulo. Fone (11) 3091-4184. Fax (11) 3091-4460. E-mail: gjdpaiva@usp.br

3 Em alemão, psicologia como ciência dizia-se Seelenkunde, e psicólogo Seelenforscher. Veja-se também, em holandês, zielkunde para psicologia. Posteriormente tornaram-se mais comuns os termos compostos com psyche.
\end{abstract}

etimológico. Não apenas o tom coloquial de Seele, mas também a associação, em inglês, da palavra com a esfera religiosa resultou na escolha do termo mind, aparentemente mais secular, menos popular e mais científico. Bettelheim (1993) não se conforma com a tradução que, no seu entender, traiu as ricas conotações da palavra no alemão, que Freud pretendeu manter. Bettelheim observa que Freud, como ateu, não utilizou a palavra em sua denotação religiosa, a não ser na analogia do analista leigo com o Seelsorger, literalmente "cura d'alma". Depois de recordar os termos "estrutura ou organização da alma", "personalidade da alma", ou seja, o mais íntimo da personalidade, "vida da alma", "inconsciente da alma", "cuidado da alma", ou seja, psicoterapia, Bettelheim resume o que Freud entende por alma: "aquilo que é de valor supremo no homem enquanto está vivo" (1993: 93).

A incompatibilidade que se faria, com o tempo, sentir entre soul e mind já fora antecipada por William James (1936) na oposição que estabeleceu, no estudo das variedades da experiência religiosa, entre o religioso sick soul e o healthy minded. Nessa tipologia, a "alma doente" é aquela atravessada pela melancolia, capaz de grandes interrogações filosóficas e capaz de salvação religiosa, de um segundo nascimento (twice-born). O religioso "de mente sadia", ao contrário, nasceu uma vez só, sorri para o mundo, dá-se bem com tudo e exibe vigor sobranceiro, que lembra a musculatura atlética. James vê mais possibilidade de experiência religiosa nas "almas" doentes do que nas "mentes" sadias. 
O que hoje alguns pesquisadores americanos e europeus, significativamente ligados à Psicologia da Religião, discutem não é, exatamente, a perda e o esforço de recuperação da alma na sua denotação religiosa, especificamente cristã, mas a perda e o esforço de recuperação do âmago profundo da pessoa. Obviamente, a familiaridade com as referências religiosas poderá ter facilitado a esses pesquisadores a percepção do problema psicológico. É também verdade que na atividade de psicoterapeutas e conselheiros mais de uma vez o plano religioso e o plano psicológico se terão confundido. Essa confusão tem suscitado veementes oposições de natureza teórica e de natureza operacional (Vergote, 2001), uma vez que, para muitos estudiosos, a relação religiosa, conquanto sustentada no psíquico, se distingue essencialmente, na intenção, dos processos psicológicos e, no caso da psicoterapia e do aconselhamento, das psicopatologias que provocam justamente a solicitação desses recursos profissionais.

Talvez a personagem de Laila, do recém-lançado Peixe Dourado, de Le Clézio (2001), sugira, em sua fragilidade indomável, o que esses autores pretendem destacar:

\begin{abstract}
“As dores de Laila”, escreve Sereza (2001, 22/9, D-3) na resenha que apresenta o livro, "não provocam pena, mas admiração. Porque ela avança, foge para a frente, nadando, como um peixe -um peixe dourado, precioso portanto-, contra a correnteza, ainda que seja, por ela, jogada de um lado para o outro. As fragilidades de Laila começam em sua origem: o rapto tiraa de seu lugar, e ela passa a ser 'do outro', a ter de conviver dai em diante sempre com o outro. A cor negra de sua pele, já no Marrocos, torna-se uma marca de sua diferença. Sua existência inicialmente depende de uma avó e dona, que morre. A primeira fuga é o inicio de uma série de encontros, tomadas de posse e novas fugas. Em resumo, Laila está sempre alienada de seu próprio corpo (uma alienação expressa nas várias violações sexuais que sofre) e de seu proprio ser (de tempos em tempos, ela percebe que se tornou, novamente, uma propriedade). Em seu caminho, Laila avança. Autodidata, lê de modo voraz. Apropria-se da cultura árabe do Marrocos, da cultura européia de Paris, da cultura negra norte-americana de Nova York e Chicago. Também aprende, entre tantos descaminhos, música".
\end{abstract}

Ouvem-se ecos da história de Severina... (Ciampa, 1987).

\section{Ameaça à pessoa}

Alguns estudos dos pesquisadores a que me referi enfeixam-se em coletâneas cujo título remete aos perigos e perdas a que a pessoa está exposta em nossos tempos: The Endangered Self (Fenn \& Capps, 1992), On Losing the Soul (Fenn \& Capps, 1995). Outros estudos assumem o tom mais neutro da epistemologia ou da atividade profissional: Heart and Psyche: the metapsychology and discourse of religious experience (Noerager, 1996), Thoughts on Psyche, Soul, and Spirit (Berghash \& Jillson, 1998), Counseling body/soul person (Malony, 1998). De passagem, observo que o estudo de Malony originariamente faria parte de uma obra interdisciplinar, de que ele foi um dos organizadores, Whatever
Happened to the Soul? Scientific and Theological Portraits of Human Nature (Brown, Murphy \& Malony, 1998).

Proponho acompanhar alguns desses autores a fim de extrair a tendência que se manifesta nesses estudos. Posteriormente será possível uma avaliação dessa tendência.

\section{Fenn e o primado da alma}

Richard Fenn, sociólogo da religião do Princeton Theological Seminary, advoga a expansão do discurso das ciências sociais acerca do self pela re-introdução da palavra alma. Considera que a tradição durkheimiana leva à perda da subjetividade, uma vez que torna o indivíduo um apêndice social. Defende, ao contrário, que a sociedade é a projeção e o duplo do indivíduo. Nessa perspectiva, deve reconhecer-se "um mistério no coração da vida social" (1995: 3), além das profundezas da natureza (vitalidade) e da sociedade (relações). Esse mistério é o que permite às pessoas uma integridade não captada pelo termo selfhood, integridade não garantida, mas que pode ser tanto conquistada como perdida e assassinada. Ela resulta do encontro entre a autonomia e espiritualidade do self, de um lado, e as coerções sociais, de outro. Entre as constrições sociais se contam as metanarrativas que, ao lado de inegáveis vantagens, homogeneizam as pessoas. $\mathrm{O}$ termo tradicional, de conotação metafísica e religiosa, para esse centro essencial é, precisamente, alma. Alguns psicoterapeutas pensam que é inerente a esse vocábulo a relação com o transcendente divino, a ponto de dever-se falar de "perda da alma" no pecado. Outros contentam-se em associar à alma uma espécie de soberania fundamental em relação à natureza e à sociedade e basta-lhes, em lugar do pecado, o abuso e a violência. Em qualquer hipótese, é na alma que se experimenta perda, pânico, abandono, rejeição, bem como quietude e íntima certeza do próprio eu. Para Fenn, estudioso dos rituais, a alma se entrevê mais pela metáfora do tempo do que pela do espaço, e são os rituais que criam o que ele chama "as estações" da alma: por eles a alma é periodicamente aliviada do peso da sociedade porquanto o passado é trazido de volta, ensejando-se o perdão. Daí a importância de se prevenir a corrupção do ritual que, se acontecer, levará à postulação de antídotos mágicos contra a perda da alma. Nesse particular, Fenn oferece interessante contraponto à análise do ritual do antropólogo Victor Turner (1976), que salva a prevalência do social sobre o individual com o termo "paradigma radical" (root-paradigm). Ao contrário, segundo Fenn, é a autonomia da alma que, por exemplo no martírio de São Tomás Becket, arcebispo de Cantuária no final do século XII, resiste às normas do esperado e vai além do paradigma radical.

\section{Capps e o locus corporal da alma}

Donald Capps (1995), psicólogo do Seminário Teológico de Princeton e ex-editor do Journal for the Scientific Study of Religion, também se refere às críticas de Bettelheim (1993) à tradução inglesa de Freud, e destaca o papel ativo da alma na "psicoterapia": a alma não é só objeto do cuidado mas 
também o locus e a fonte da regeneração, física e psíquica (1995: 139). Na visão de Capps é preciso restituir à alma seu lugar na topografia do ser humano. Não se pode confundi-la com o espírito, entendido seja como pneuma, na tradição cristã, seja como mind, na tradição intelectualista. A alma se refere propriamente aos vales e não aos picos da experiência humana e é dela que geme o homem em seus De profundis... Maslow estaria enganado ao sugerir que a mais alta realização humana estaria nas experiências de pico, entre as quais se poderiam contar experiências de cunho religioso: primeiro, porque as experiências de pico podem ser moralmente condenáveis (como no êxtase do gozo do psicopata) e, segundo, porque valiosas experiências humanas, inclusive de natureza religiosa e cristã, ocorrem no que as culturas antigas consideraram a sede da vida. Capps aqui se refere às localizações corporais do princípio vital e a experiências religiosas associadas à fisiologia corporal. Embora pudesse referir-se aos vários órgãos associados, na chamada "psicologia hebraica" a nephesh, a saber o coração, o fígado, os rins, as entranhas, o sangue, mas nunca o cérebro (Barr, 1983), Capps propõe, com uma ponta de ironia, a relocalização da alma como questão "pós-moderna" (1995: 147) e explora a antiga localização da alma no fígado, único órgão a se regenerar. Lembra que o fígado, em grego chole (donde cólera, colérico, melancolia e melancólico) e que, acrescento, deu em português o adjetivo figadal, só perdeu a referência à alma quando a medicina se separou da religião. E ainda assim não de todo, se levarmos em conta que a melancolia, entre os gregos considerada a "quintessência da patologia da alma" (1995: 150), foi, no campo cristão, ora identificada com o pecado capital da acídia ou tristeza, ora com a invasão do demônio do meio-dia, ora com um desequilíbrio dos humores, e foi por longo tempo, na linguagem comum, associada à amargura, ao acabrunhamento, ao ressentimento, e hoje em dia à depressão. A patologia da alma, identificada com a melancolia, ocupa um lugar de destaque na psicologia da religião de William James (1936) que atribui à alma doente (sick soul) especial propensão para as experiências místicas. É interessante notar que as experiências dessa natureza vêm acompanhadas de mudanças fisiológicas como as descritas por James: "alguma coisa até então sólida dentro de meu peito desapareceu por completo" e foi substituída por "um horrível temor na ponta de meu estômago" (1936: 157). Na linha dessas associações, Capps discute a famosa alegação de Erikson de que "a grande ruptura" teológica de Lutero se deu enquanto ele estava sentado no vaso sanitário. Lutero sofria de prisão de ventre e de retenção urinária crônicas: "assim, nesse momento criativo a tensão de noites e dias de meditação escoou aliviada de seu inteiro ser -e ninguém que tenha lido Lutero pode duvidar de que seu inteiro ser incluía sempre os intestinos" (Capps, 1995: 154, citando Erikson). "Para Erikson", continua Capps, "existe alguma coisa profundamente fisiológica no novo entendimento que Lutero tem de Deus como de alguém que não mais espreita na periferia do espaço e tempo, mas antes move-se de dentro de nós e é, por isso, num sentido muito real, o que age em nós" (Capps, 1995: 154, citando Erikson). Capps fala também da expulsão do cálculo renal como de uma experiência da graça divina, e cita o cirurgião Richard Selzer, para quem deixar de sentir dor depois que se desprende a pedra do rim não é menos que sentir-se tocado pela mão de Deus. Selzer se apoia no testemunho de um paciente que escreveu no diário: "Bem de manhã; hoje é, pela grande graça de Deus, o quarto solene dia depois de minha operação" (Capps, 1995: 155). Em resumo, a alma, ligada como está aos órgãos e funções do corpo, merece o cuidado do terapeuta, porque aponta para sentimentos e emoções básicas, que podem, inclusive, integrar-se num quadro de referência religioso.

\section{Wikström e o centro do ser humano}

Owe Wikström, da Universidade de Uppsala, Suécia, e atual ocupante da cadeira de Psicologia da Religião fundada por Hjalmar Sundén, propõe que ao contrário da desmitificação e desconstrução radicais operadas na Psicologia moderna, que levou à perda da alma, se proceda a uma remitificação e reconstrução. Se o ser humano é um ente racional, condicionado pelo contexto social e pelas forças biológicas e psicológicas, é também um ser moral e espiritual, um centro de liberdade e de responsabilidade. Essa é sua dignidade. "Por que não chamar a isso de 'alma'?" (Wikström, 1995: 130). Esse centro, que se abre também para o invisível e o transcendente, não pode deixar de ser incluído em sua visada pelo psicólogo fiel aos dados. Para superar a legítima desconstrução da atual psicologia têm contribuído algumas correntes, como a psicologia do ego, a psicologia humanista e a psicologia cognitiva. Wikström propõe, no entanto, que também se deve reler clássicos como Dostoievski, que "aponta o mistério da autonomia e espiritualidade e cria gestalts que unem corpo, psique, espiritualidade e moralidade" (Wikström, 1995: 122). Dostoievski, em particular, superou o idealismo romântico e o realismo fisiológico e social da época, voltando-se para o realismo que descreve neste trecho: "tenho minha própria visão da realidade, e o que a maioria das pessoas chama de quase fantástico e excepcional, é para mim algumas vezes a própria essência do real" (Wikström, 1995: 132). Extremos morais e existenciais, como o santo e o ateu, não podem, por isso, ser reduzidos a simples disposições mentais, pois resultam da liberdade. Recuperar a alma não é, então, uma operação clandestina, senão o resultado da observação empírica, a que o psicólogo deve estar afeito. Dostoievski, por exemplo em Crime e Castigo, descobre a alma de seus personagens porque acentua o caráter racional e irracional do homem. Se se pode caracterizar a modernidade, nas ciências do homem, como a "hermenêutica da suspeita", Dostoievski foi um moderno. Mas por reconduzir o homem a sua natureza de portador de um mistério, Dostoievski foi além da modernidade clássica e abraçou a "segunda ingenuidade". Com isso, escapou da superstição científica, que consiste em excluir do objeto a parte de realidade que o método não lhe permite considerar ou, em outras palavras, deixar que a redução metodológica se transforme em reducionismo ontológico, que leva à perda da alma. Para Wikström, portanto, não se leva em conta a alma do homem quando se 
encaixa o homem em modelos sociais gerais ou em teorias psicológicas. Esse o risco da moderna psicologia: reduzir a individualidade do homem a metanarrativas como leis físicas, estruturas semânticas, forças psicodinâmicas ou processos sociais. Finalmente, como psicólogo da religião, Wikström não está afirmando ou negando a transcendência fora do sujeito humano, mas leva em conta, na reconstrução do indivíduo real, sua liberdade e responsabilidade pessoal também em relação à transcendência. Nessa inclusão da autonomia livre e responsável do homem é que consiste, segundo ele, a "recuperação da alma" e a revalorização da psicologia.

\section{Noerager e a centralidade do coração}

Troels Noerager, da Universidade de Aarhus, Dinamarca, não fala de alma mas de coração, e discute as implicações, para o tema do self em perigo da mudança da metapsicologia, de pré-científica para científica (Noerager, 1992). Em trabalho mais recente (Noerager, 1996), o autor propõe o modelo do coração, tradicional no cristianismo (coração poderia ser um Urwort), como mais fundamental do que o modelo da psique, da psicologia científica. A idéia de coração como "senso nuclear de que somos um ser de corpo e alma" (1992: 48) coincide com o sentido de alma que vimos apresentando. Segundo Noerager, assistimos hoje a um "eclipse" do coração porque o mundo da vida, expresso na linguagem comum, não se reencontra com a cultura dos especialistas. Especificamente, o coração da tradição religiosa, da psicologia comum e das psicologias nativas (indigenous psychologies; Heelas \& Lock, 1981), deu lugar ao inconsciente ou ao self dos estudiosos. Em outras palavras, existe um hiato hermenêutico entre a metapsicologia pré-científica da religião e da linguagem comum e a metapsicologia científica. Noerager propõe como tarefa à Psicologia da Religião "criar uma metapsicologia capaz de integrar o discurso tradicional do coração e clarificá-lo à luz da moderna Psicologia" (1992: 54). Para isso discute, como exemplo de uma primeira tentativa, a obra do revivalista americano do século XVIII, Jonathan Edwards (1992 e 1996), e o o hinário devocional da Igreja Luterana Dinamarquesa (1996). Edwards, autor de Treatise Concerning Religious Affections, estava interessado no fenômeno da conversão verdadeira. Influenciado pelo empirismo de Locke, pensava que ela só acontecia quando a pessoa obtinha, além de um conhecimento especulativo, um "conhecimento sensível”, isto é, relacionado com os afetos e a vontade. Esse é o "senso do coração", conhecimento que envolve as afeições, "mola" da ação, e a vontade, que inclina a pessoa à ação correspondente. Para Edwards, as afeições se estendem a sensações corporais ao redor do órgão do coração. Edwards conseguiu de algum modo aproximar a tradição bíblica e a linguagem ordinária a uma metapsicologia incipiente, a de Locke. Mas o êxito não foi duradouro, pois o conceito lockeano de "consciência", aquele conhecimento completo que o indivíduo tem do que vai nele, baniu o ideal religioso da humildade diante de Deus, o único que perscruta o enigma humano. Um se- gundo campo de pesquisa da transposição de metapsicologias é o conjunto de hinos religiosos da Igreja Luterana Dinamarquesa. O Hinário dessa Igreja compreende 750 hinos, compostos entre os séculos XVII e XIX, e mais 150 hinos editados em 1994. Segundo Noerager, o Hinário é para os cristãos dinamarqueses uma fonte de devoção pessoal "mais importante do que a própria Bíblia” (1996: 359). No Hinário, a palavra singular mais freqüente é coração, com o sentido metapsicológico de "vazio, estado de necessidade, anelo, fome e sede, atraído e arrastado" (1996: 360), e com o sentido metafórico do amor. O coração é órgão de conhecimento, pois "sente, percebe, saboreia, entende" (1996: 361) e, como domínio-fonte, é "quarto, campo, lâmpada, luz, [com as qualidades de] duro/mole, aberto/fechado, quente/frio" (1996: 361). Nos 150 hinos mais recentes do Apêndice ao Hinário, o autor constata que a proeminência do coração decaiu quantitativa e qualitativamente, mas observa uma nova tendência de valorização da vitalidade corporal. Aliás, essa nova valorização do corpóreo confirma a base corporal de todo o processo metafórico. Noerager (1996) se confessa, no entanto, perturbado com o desaparecimento de elementos fundamentais da relação do homem com Deus, a saber a dominação do pecado, a preparação divina e a moradia da graça e do Espírito Santo. Noerager (1996) apresenta, então, o grande psicólogo dinamarquês da religião, Villiam Groenbaek, como quem constrói com êxito uma ponte entre o entendimento tradicional do ser humano e a moderna psicologia. Na discussão de Noerager, Groenbaek, fiel à característica da psicologia dinamarquesa de "um senso de reconhecimento do valor da vida interior" (Noerager, 1996: 364), procura o equivalente psicológico do papel do coração no experienciar religioso. Inicialmente, ainda muito ligado à Escola de Dorpat, Groenbaek fala das "funções do eu", mas nos últimos escritos prefere a expressão "elementos centrais", isto é a "parte profunda e central da personalidade que é tocada, ativada e se comunica" (1996: 365). Com esse esforço de descrição fenomenológica da linguagem do coração, seguida pela consideração comparativa dessa linguagem com a da psicologia, Groenbaek consegue esclarecer psicologicamente alguns conceitos da experiência religiosa. Com isso pensa Noerager que é possível conciliar, embora sempre num ir-e-vir da reflexão, a metapsicologia religiosa pré-científica e o discurso da psicologia científica. Pensa também que, com esse procedimento, a psicologia deixa de reprimir a linguagem do coração e de impedir o adequado discurso religioso e moral pronunciado acerca do íntimo do ser humano por seus predecessores históricos, a saber a teologia, a filosofia e a estética. Finalmente, com isso a própria psicologia da religião deixa de se considerar simples subdisciplina da Psicologia, pois passa a levar em conta a linguagem cotidiana, os diversos modelos culturais da psique, as várias psicologias nativas.

\section{Malony e a capacidade de transcendência}

H. Newton Malony, da Escola de Pós-Graduação em Psicologia do Fuller Theological Seminary, de Pasadena, 
defende a reintrodução do vocábulo alma na terminologia da atividade profissional do aconselhamento (Malony, 1998). Com efeito, a profissão do conselheiro, pastoral ou secular, a muitos parece estar-se tornando uma profissão ...sem alma, dada a ênfase exagerada na saúde física e nos comportamentos de adaptação social. Não que a cultura geral se tenha esquecido da alma: o interesse pela reencarnação e pela transmigração, alimentado pela Nova Era, a busca de contato com os espíritos dos mortos, a curiosidade pelas chamadas experiências de quase morte, a música soul testemunham alguma permanência de uma referência transcorpórea. A alma está ausente, então, da linguagem cotidiana das igrejas tradicionais e das ciências. Malony (1998; veja-se também 1997) pensa que a Psicologia da Religião pode colaborar com a prática profissional do aconselhamento cultivando uma dimensão sui generis da pessoa, que a cultura ocidental cristã liga precisamente ao conceito e ao termo de alma. $\mathrm{O}$ autor não pretende dirimir a questão ontológica ou metafísica da dualidade ou da unidade corpo/alma da pessoa: basta-lhe a pessoa como unidade psicossomática dotada de uma capacidade transempírica, que não se limita à simples busca de sentido, mas se estende à capacidade espiritual de "buscar uma dimensão mais profunda, transfuncional para a vida", "que muitas vezes se expressa religiosamente" (1998: 231), isto é numa relação interpessoal com o divino. Malony é cauteloso ao referir-se a essa relação com o divino: não se trata de uma exigência da unidade psicossomática do homem mas de uma capacidade, que pode ser atualizada ou não pela pessoa, em dependência da cultura, das relações interpessoais e de variáveis de personalidade. Por isso, o apelo à alma, e muito menos em sua denotação religiosa, não é necessário para a prática do aconselhamento. Mas não deve ser a priori rejeitado, pois naquelas pessoas em que essa capacidade é atualizada, a abertura para um Deus pessoal fornece uma plenitude de vida psíquica que ultrapassa a própria integridade dos processos psicológicos. Nesse sentido, Malony declara que recuou da posição que postulava a wholeness (integridade) como prévia à holiness (santidade) (1998: 236), opondo-se, portanto, ao modelo da hierarquia de necessidades, de Maslow.

\section{Discussão das considerações e propostas.}

O tema do self em perigo acompanha as discussões de Lasch do self mínimo, de Cushman do self vazio e, até certo ponto, de Gergen do self saturado. Há uma impressão geral de que algo de profundo se perdeu, na cultura ocidental, do indivíduo ou da pessoa. Essa perda é atribuída aos desdobramentos contemporâneos da modernidade e da pósmodernidade, com particular atenção ao processo da secularização tal como se deu. Penso que essa perda também pode ser atribuída, em parte, ao dimensionamento destacadamente psicossocial que se vem dando à questão da identidade.

A recuperação ou a restauração do self é objeto do interesse de vários psicólogos, dentre os quais se destacam os psicólogos da religião. Esses psicólogos vêm propondo a revalorização de termos como alma e coração. A proximidade com as tradições religiosas cristãs desses psicólogos e o reconhecimento da sacralidade do ser humano certamente favorecem o interesse que demonstram. Porém não só não é necessário -para a discussão do presente mal-estar- o enquadramento religioso da perda e da recuperação do self, como mesmo os psicólogos da religião não propõem esse enquadramento, conseguindo geralmente distinguir entre alma/coração como âmago da pessoa e a eventual abertura desse âmago para a transcendência religiosa.

A revalorização da palavra alma, em particular, encontra no próprio Freud um apoio fundamental, enquanto Freud, escrevendo em alemão, utilizou muitas vezes a palavra Seele em lugar de Geist, que é o correspondente de espírito ou mente. Com essa opção, Freud permitiu que persistisse a necessária ambigüidade de definição do núcleo íntimo da existência pessoal. Para Freud, alma não tinha nada de religioso -embora não sejamos, por isso, obrigados a acompanhálo na recusa à abertura da alma para a religiosidade. Sua tradição judaica permitia-lhe, provavelmente, captar o vernáculo alemão com as ressonâncias do nephesh hebraico, "ser vivo, sede da vida, eu mesmo" (Barr, 1983: 266), de natureza não diferente do corpóreo. Nesse sentido, Freud ao mesmo tempo que propôs uma metapsicologia repleta de distinções (muitas delas hipotéticas), manteve a solidez da unidade humana fundamental, a alma, não só como objeto de cuidado mas também como fonte de cuidado de si mesma, capaz de regenerar-se e de reintegrar-se.

Creio que para ter valor como constructos psicológicos, alma e coração têm de abstrair da denotação e da conotação religiosa. Abstrair não é negar mas colocar entre parênteses. Nesse ponto, não vejo as "doenças da alma" ou as "turbações do coração" como doenças religiosas, isto é, seqüelas do pecado, nem a restauração da alma como salvação divina. Talvez se pudesse aceitar a expressão doenças e restaurações "espirituais", se isso não induzisse o perigo de uma outra dicotomia, a saber a de alma versus espírito. O psicólogo junguiano James Hillman, citado em Capps (Fenn \& Capps, 1995), atribui essa distinção ao cristianismo paulino, que teria tido como efeito o menosprezo da "alma" em benefício do “espírito". É possível que tenha havido essa leitura, mas curiosamente é São Paulo (I Cor. 2, 14s.) que preserva a distinção entre alma e espírito, reservando para o espírito (entenda-se Santo) a salvação e para o homem o funcionamento psíquico (pneumatikòs ánthropos/psychikòs ánthropos). Essa distinção não é, porém, aceita por todos (Belzen \& Wikström, 1997) e foi recentemente objeto de debates calorosos no 8.o Simpósio dos Psicólogos Europeus da Religião, em Sigtuna, Suécia (Wikström, DeMarinis \& Cetrez, 2000).

Para concluir, penso que a discussão da perda e recuperação da alma ou da perda e recuperação da metapsicologia do coração leva-nos a sondar novamente a linguagem comum, a apreciar a linguagem dos escritores e dos artistas plásticos e a redescobrir, como o fizeram Heider (1970), Heelas e Lock (1981) e outros, a organização subjacente à aparente desordem e imprecisão da linguagem comum. Um autor tão distante de nossos problemas, como o japonês Endo 
Shusaku, por exemplo, põe estas palavras na boca do personagem covarde: "por causa do medo da dor física, vou provavelmente continuar traindo minha própria alma" (1984: 42). Um levantamento, em nosso meio, como o iniciado por Massimi e Silva (2001) e por Mahfoud (2001), da linguagem cotidiana e da literatura, inclusive da religiosa expressa nos cânticos tradicionais, seria de interesse para revalorizar a percepção propriamente cultural de muitas de nossas realidades e para vivificar o discurso, demasiado mentalista, da psicologia e da psicoterapia.

\section{Referências}

Barr, J. (1983). Hebraic psychology. Em R. Harré \& R. Lamb (Orgs.). The Encyclopedic Dictionary of Psychology. Oxford: Blackwell, 266s.

Belzen, J.A. \& Wikström, O. (Orgs.) (1997). Taking a Step Back. Assessments of the Psychology of Religion. Uppsala: Acta Universitatis Uppsaliensis.

Bettelheim, B. (1993). Freud e a alma humana. (Alvaro Cabral. Trad.) São Paulo: Cultrix (Trabalho original publicado em 1982).

Berghash, R. \& Jillson, K. (1998). Thoughts on Psyche, Soul, and Spirit. Journal of Religion and Health, 37, 313-322.

Brown, W.S., Murphy, N. \& Malony, H.N. (Orgs.) (1998). Whatever Happened to the Soul? Scientific and Theological Portraits of Human Nature. Minneapolis: Fortress.

Capps, D. (1995). Enrapt Spirits and the Melancholy Soul: The Locus of Division in the Christian Self and American Society. Em R.K. Fenn \& D. Capps (Orgs.), On Losing the Soul. Albany: State University of New York Press, 137-169.

Ciampa, A.C. (1987). A estória do Severino e a história da Severina. Um ensaio de Psicologia Social. São Paulo: Brasiliense.

Endo, S. (1984). Stained Glass Elegies. (Van C. Gessel.Trad.). London \& Washington: Peter Owen. (Trabalho orginal publicado em 1959).

Fenn, R.K. \& Capps, D. (1992). The Endangered Self. Princeton, NJ: Princeton Theological Seminary.

Fenn, R.K. \& Capps, D. (Orgs.) (1995). On Losing the Soul. Essays in the Social Psychology of Religion. Albany: State University of New York Press.

Freud S. (1993). Gesamtregister. Gesammelte Werke. Frankfurt a. Main: S. Fischer. Vol. XVIII, 555s. (1968).

Heelas, P. \& Lock, A. (Orgs.) (1981). Indigenous Psychologies. London: Academic Press.

Heider, F. (1970). Psicologia das Relações Interpessoais. (D. M. Leite, Trad.). São Paulo: Pioneira. (Trabalho original publicado em 1958).

James, W. (1936). The Varieties of Religious Experience. A Study in Human Nature. New York: The Modern Library ( Trabalho original publicado em 1902).

Le Clézio, J.-M.G. (2001). Peixe Dourado. São Paulo: Companhia das Letras (1997).

Mahfoud, M. (2001). Necessidade, desejo e exigências. Cultura como âmbito da experiência. Em G.J.de Paiva (Org.), Entre Necessidade e Desejo. Diálogos da Psicologia com a Religião. São Paulo: Loyola, 79-89.
Malony, H.N. (1997). A Proposal for a Psychology of Religious Expression. Em J.A.Belzen \& O.Wikström (Orgs.), Taking a Step Back. Assessments of the Psychology of Religion. Uppsala: Acta Universitatis Upsaliensis, 127-136.

Malony, H.N. (1998). Counseling Body/Soul Persons. The International Journal for the Psychology of Religion, 8, 221-242

Massimi, M. \& Silva, P.J.C. (2001) (Orgs.), Os olhos vêem pelo coração. Conhecimento psicológico das paixões na história da cultura brasileira dos séculos XVI a XVII. Ribeirão Preto: Holos /Fapesp.

Noerager, T. (1992). The eclipse of the heart: The shift from prescientific to scientific metapsychology, and its implications for the theme of the endangered self. Em R.K. Fenn \& D.Capps (Orgs.), The Endangered Self. Princeton, NJ, The Center for Religion, Self and Society. Princeton Theological Seminary. Monograph Series, number 2, 47-57.

Noerager, T. (1996). Hjerte og Psyke. Studier i den religioese oplevens metapsykologi og diskurs. [Heart and Psyche: The metapsychology and discourse of religious experiencing]. Postdoctoral thesis. Koebenhavn: Anis. Summary, 356-369.

Prado, A. (2001). Filandras. Rio de Janeiro: Record.

Sereza, H.C. (2001, 22 de setembro). Uma personagem que vence a corrente. O Estado de São Paulo, D-3.

Turner, V. (1976). Religious paradigms and political action: 'The murder in the cathedral' of Thomas Becket. Em F.R. Reynolds \& D.Capps (Orgs.), The Biographical Process. Studies in the History and Psychology of Religion. The Hague/Paris: Mouton, 153-186.

Vergote, A. (2001). Necessidade e desejo da religião na ótica da psicologia. Em G.J.de Paiva (Org.), Entre Necessidade e Desejo. Diálogos da Psicologia com a Religião. São Paulo: Loyola, 9-24.

Wikström, O. (1995). Soul recovery through remystification: Dostoyevski as a challenger of modern psychology. Em R.K. Fenn \& D. Capps (Orgs.), On Losing the Soul. Albany: State University of New York Press, 119-136.

Wikström, O., DeMarinis, V. \& Cetrez, Ö. (2000). Program and Abstracts. 8th Symposium for Psychologists of Religion, Sigtuna (Suécia), 33s. 